\title{
Combining short stent implantation and drug-eluting stenting for routine use yields a low restenosis rate Ulrich Dietz*, Cheryl Dauer and Heinz Lambertz
}

Address: German Clinic for Diagnostic, Wiesbaden, Germany

Email: Ulrich Dietz* - dietz.kardio@wiesbaden.de; Cheryl Dauer - dauer.kardio@dkd-wiesbaden.de; Heinz Lambertz - lambertz.kardio@dkdwiesbaden.de

* Corresponding author

Published: 13 December 2005

Current Controlled Trials in Cardiovascular Medicine 2005, 6:18 doi:10.1 |86//468-6708-6-18

This article is available from: http://cvm.controlled-trials.com/content/6/I/l8

(c) 2005 Dietz et al; licensee BioMed Central Ltd.

This is an Open Access article distributed under the terms of the Creative Commons Attribution License (http://creativecommons.org/licenses/by/2.0), which permits unrestricted use, distribution, and reproduction in any medium, provided the original work is properly cited.
Received: 2I September 2005

Accepted: 13 December 2005

\begin{abstract}
Background: Stent length serves as a predictor of restenosis in use of bare metal stents (BMS). This has been demonstrated in a feasibility study that used a single short BMS implant $(<9 \mathrm{~mm})$ in a high proportion of lesions; the study observed a low rate of restenosis.

Methods: We performed a pilot prospective study to investigate in a series of consecutive patients the immediate and long-term effects of implantation of either I) a single short BMS for all lesions with low probability of restenosis or 2) a drug-eluting stent (DES) for all other lesions.

Results: The 200 patients studied had 236 coronary artery lesions that were treated with short BMS in $168 / 236$ patients (7I.2\%) and with DES in 68/236 patients (28.8\%). Angiographic success was achieved in 230/236 lesions (97.5\%) and procedural success in 194/200 patients (97.0\%). Restenosis occurred in 15/153 lesions (9.8\%) after short BMS, in 3/62 lesions (4.8\%) after DES, and in $18 / 215$ of all lesions $(8.4 \%)$ angiographically controlled after six to eight months. Target vessel revascularization was performed in $16 / 218$ lesion (7.4\%).

Conclusion: Most of the coronary artery lesions in this small group of consecutive patients were treated sufficiently with a single BMS implant. This differential approach of treating suitable lesions in medium- to large-sized vessels with a single short BMS device and treating all other lesions with a DES implant resulted in a low incidence of restenosis.
\end{abstract}

\section{Introduction}

Sirolimus- and Tarcolimus-eluting stents reduce restenosis rates in larger vessels and in longer lesions as compared to bare metal stents (BMS) $[1,2]$. The low restenosis rates found with these drug-eluting stents (DES) suggests that all lesions could benefit from this type of stent. One concern about their use in the majority of lesions relates to cost, since these stents are much more expensive than bare metal stents [2]. A recently published cost-effectiveness analysis showed that treatment with DES would impart cost savings in patients with a BMS target vessel revascularization (TVR) rate $>20 \%$ and cost effectiveness in patients with a BMS TVR rate $>12 \%$ [3]. Stent length and vessel size represent primary factors affecting BMS restenosis rates [4]. Moreover, implantation of a BMS that is longer than the lesion itself increases the risk of restenosis independently [5].

In a previous prospective study, we demonstrated that stenting of only the most significant obstruction of a 
lesion after balloon dilatation or use of direct stenting alone was feasible in a high proportion of cases yielding low rates of stenosis. [6]. In another prospective study, we observed that short stenting significantly reduced the restenosis rate as compared to conventional stenting, which involves placement of the stent over the entire stenotic segment of a vessel [7]. In this latter study, vessel size only was found to predict restenosis after short stenting. In the present pilot study, we report on our ongoing evaluations by comparing a) short stenting with BMS in lesions with low probability of restenosis to b) stenting with DES in lesions with predicted restenosis rates of $>10 \%$ after BMS.

\section{Methods \\ Patients}

Two hundred consecutive patients with symptoms of angina pectoris, a positive exercise tolerance test, or both, and coronary arteries with $>60 \%$ diameter stenoses were included in this study. Patients with lesions in the left main artery and patients treated for myocardial infarction were excluded.

\section{Procedures}

Clopidogrel $75 \mathrm{mg}$ was administered daily starting 4 days prior to elective interventions. All patients received acetylsalicylic acid for at least 14 days prior to intervention and heparin (5000 IU) as an intravenous bolus before the procedure and then by infusion during the procedure, at dose levels targeting a 2.5 -fold prolongation of activated prothrombin time (aPTT). Percutaneous transluminal coronary angioplasty was performed initially in most cases using semi-compliant balloons. The balloon length was $15 \mathrm{~mm}$ for short lesions $(<10 \mathrm{~mm})$ and $20 \mathrm{~mm}$ for longer lesions. Balloon sizes were selected to achieve a balloon/ artery ratio of 1.0 to 1.2 when fully expanded at $>10 \mathrm{~atm}$.

\section{Use of BMS stents}

A short BMS $(<10 \mathrm{~mm})$ was considered for vessels $>2.7$ $\mathrm{mm}$, to be implanted either:

1. By direct stenting if the lesion had a length $<10 \mathrm{~mm}$ located in the proximal part of the left anterior descending coronary artery, or of the right coronary artery; or

2. After balloon dilatation of a longer lesion if angiography performed 5 min after the initial intervention showed a residual stenosis $>30 \%$ that reflected a lesion $\leq 10 \mathrm{~mm}$ in length, in the absence of a longer dissection.

\section{Use of DES stents}

For all other lesions not suitable for a short BMS, a DES was implanted.

All stents, premounted on semi-compliant balloons, were sized to achieve a stent to artery ratio of $1.1 \mathrm{at}>12 \mathrm{~atm}$.
The short BMS included 168 MultiLink stents, while the DES involved 53 Cypher stents and 15 Taxus stents. After the procedure, all patients were prescribed acetylsalicyclic acid $100 \mathrm{mg}$ daily indefinitely. For patients who had received a stent, clopidogrel $75 \mathrm{mg}$ daily was also prescribed for 4 weeks. Patients with hypercholesterolemia were strongly advised to take a cholesterol synthesis inhibitor regularly. Six months and eight months after implantation of the BMS and DES implants, respectively, control angiography was performed using projections that were identical to those employed during the intervention.

\section{Quantitative coronary angiography}

The CAAS II Research System (Pie Medical Imaging, Maastricht, The Netherlands) was used for automated contour detection and quantification. The system and validation data are described elsewhere [8]. The measurement procedure was previously published in detail [9]. Angiography was performed before and after all interventions and at angiographic follow-up using identical projections and analyses. Frames were selected as recommended by Herrington and Walford [10]. Analyses followed the guidelines proposed by Reiber $e t$ al. [11]. Lesion length was the distance along a vessel segment characterized by a diameter stenosis $>50 \%$, as compared to the reference segment. Lesion length, mean diameter within the lesion (mean stenosis diameter), and minimum lumen diameter (MLD) were calculated for the target vessel segment. In addition, mean diameter stenosis and minimum lumen diameter were measured at a distance of $5 \mathrm{~mm}$ from each stent edge. Restenosis was defined as $>50 \%$ in segment diameter stenosis at angiographic follow-up.

\section{Statistical analyses}

Continuous data are expressed as the mean \pm the standard deviation. Chi-square tests were used to compare categorical variables, and the Mann-Whitney test was employed to compare continuous variables. Statistical significance was accepted at $p<0.05$.

\section{Results}

The study included 200 consecutive patients with a total of 236 treated lesions (mean 1.2 lesions/patient). Baseline clinical and angiographic characteristics are shown in Tables 1 and 2. Balloon dilatation was performed initially in $198 / 236(83.9 \%)$ coronary artery lesions, and direct stenting with a short BMS was performed in 38/236 (16.1\%). A short BMS after balloon angioplasty was judged suitable in 130/236 (55.1\%) lesions, and a DES was implanted in 68/236 (28.8\%) lesions that were deemed to be unsuitable for BMS. An additional stent was implanted subsequent to the first procedure in cases involving persistent residual stenosis $>30 \%$ or a dissection in nine cases $(5.4 \%)$. Three DES implants could not be 
Table I: Baseline characteristics

\begin{tabular}{ll}
\hline Variable & All patients N = 200 \\
\hline Age (years) & $62 \pm 10$ \\
Males & $154(77.0 \%)$ \\
CCS III - IV & $78(38.0 \%)$ \\
Hypertension & $153(76.5 \%)$ \\
Hypercholesterinemia & $155(77.5 \%)$ \\
Diabetes mellitus & $48(24.0 \%)$ \\
Multivessel coronary disease & $97(48.5 \%)$
\end{tabular}

\pm : Standard deviation.

CCS: Canadian Cardiovascular Society classification.

deployed; the results of the balloon angioplasty were not further manipulated.

As compared to BMS implantation, DES implants were used more frequently for side branch lesions $(p=0.03)$ and longer lesions $(p<0.0001)$ in smaller vessels $(p=$ $0.0001)$. The DES devices were significantly smaller $(2.7 \pm$ $0.2 \mathrm{~mm}$ vs. $3.0 \pm 0.4 \mathrm{~mm}, \mathrm{p}<0.0001)$ and longer $(18.4 \pm$ $5 \mathrm{~mm}$ vs. $8.3 \pm 0.2 \mathrm{~mm}, \mathrm{p}<0.0001)$ than the short BMS implants (Table 3).

Angiographic analysis revealed that residual plaque outside the short BMS contributed to $25 \%$ to $45 \%$ residual diameter stenosis in 15/168 (8.9\%) lesions, and none after DES implantation.

\section{Immediate results}

Angiographic success (post-intervention diameter $<30 \%$ within the stent) was the same for short BMS and DES $(164 / 168 ; 97.6 \%$, and $66 / 68 ; 97.0 \%$ ) as was procedural success (angiographic success and no MACE [myocardial infarction, reintervention, death]), which was accomplished in $194 / 200$ (97.0\%) patients (Table 4). Major cardiac events (myocardial infarction, repeat target vessel revascularization or death) occurred in two patients.

\section{Clinical follow-up}

Angina pectoris (Canadian Cardiovascular Society classes III or IV) recurred during follow-up in 3 patients, and major cardiac events were experienced by 3 patients, of whom 2 died during the 8-month follow-up period while the third underwent elective coronary artery bypass grafting. Target vessel revascularization was performed in 16/ $218(7.4 \%)$ lesions at follow-up.

\section{Angiographic follow-up}

In 180/192 eligible patients, angiography was repeated at $193 \pm 25$ days on 215/226 (95.1\%) lesions (Table 5). Restenosis occurred in 18/215 (8.4\%) of all lesions, in 15/ $153(9.8 \%)$ lesions treated with a short BMS and in 3/62 $(4.8 \%)$ lesions after DES. According to univariate analysis,
Table 2: Lesion baseline characteristics

\begin{tabular}{ll}
\hline Variable & All lesions N = 236 \\
\hline De novo lesion & $227(94.9 \%)$ \\
Total occlusion & $8(3.4 \%)$ \\
Left anterior descending artery & $83(35.2 \%)$ \\
Left circumflex artery & $53(22.5 \%)$ \\
Right coronary artery & $73(30.9 \%)$ \\
Coronary artery side branches & $23(9.7 \%)$ \\
Venous coronary bypass & $4(1.7 \%)$ \\
Lesion morphology & \\
Eccentric & $157(66.5 \%)$ \\
Diffuse & $33(14.0 \%)$ \\
AHA type A/BI & $93(39.4 \%)$ \\
AHA type B2/C & $143(60.6 \%)$ \\
\hline
\end{tabular}

AHA: American Heart Association.

the restenosis rate was higher when an additional stent had been implanted after short BMS. No other clinical or angiographic parameter was associated with increased risk of restenosis.

\section{Discussion}

Although BMS implants in many lesions have reduced the restenosis rate as compared to PTCA, stent implantation in the clinical setting continues to yield restenosis rates exceeding 20\% [12]. In general, in-stent restenosis (ISR) can be predicted based on stent size and stent length and based on the presence of diabetes mellitus [4,13]. Previous analyses have demonstrated that stent length can serve as a predictor of ISR independent of lesion length $[14,15]$. A recent meta-analysis of intervention trials noted that stent length exceeds lesion length in about $90 \%$ of interventions; this excess in stent length increased the risk of ISR independent of other parameters in bare metal stenting [5].

In a previous study investigating the feasibility of routinely shortening stent length to cover only those vessel segments with significant obturating plaque and leaving nonobstructing plaque material unstented, we found it suitable to use a single stent $<10 \mathrm{~mm}$ in $60 \%$ of all stent implantation procedures [6]. The 6-month angiographic restenosis rate in this study was $16 \%$ for all stented lesions. In a prospective study of 400 consecutive patients who underwent short stenting of their coronary artery lesions, we compared immediate and long-term results with a matched-pair control group of patients treated earlier with conventional-length stents. We found a significantly lower restenosis rate after short stenting, with no difference in the procedural success rates [7]. Vessel size was the only predictor of ISR after short stenting. In $91 \%$ of all lesions stented, the TVR rate was $<10 \%$ in all vessels $>2.7 \mathrm{~mm}$. 
Table 3: Procedural data and baseline characteristics of quantitative coronary angiography

\begin{tabular}{lllll}
\hline Variable & Short BMS $n=168$ & DES $n=68$ & $p$ & All Stents $n=236$ \\
\hline Stent length $(\mathrm{mm})$ & $8.3 \pm 0.2$ & $18.4 \pm 5$ & $<0.0001$ & $11.2 \pm 8$ \\
Nominal device diameter $(\mathrm{mm})$ & $3.0 \pm 0.4$ & $2.7 \pm 0.2$ & $<0.0001$ & $2.9 \pm 0.5$ \\
Inflation pressure (atm) & $13 \pm 3$ & $13 \pm 3$ & $\mathrm{~ns}$ & $13 \pm 3$ \\
Device/artery ratio & $1.12 \pm 0.1$ & $1.14 \pm 0.1$ & $\mathrm{~ns}$ & $1.13 \pm 0.1$ \\
Reference diameter (mm) & $3.1 \pm 0.4$ & $2.8 \pm 0.3$ & $<0.0001$ & $3.0 \pm 0.5$ \\
Diameter stenosis before (\%) & $74 \pm 14$ & $76 \pm 13$ & $<0.0001$ & $75 \pm 14$ \\
MLD before (mm) & $0.77 \pm 0.4$ & $0.73 \pm 0.4$ & $\mathrm{~ns}$ & $0.76 \pm 0.3$ \\
Plaque area $\left(\mathrm{mm}^{2}\right)$ & $9 \pm 5$ & $14 \pm 7$ & 0.0001 & $10 \pm 6$ \\
Lesion length $(\mathrm{mm})$ & $8.7 \pm 3$ & $14.6 \pm 5$ & $<0.0001$ & $9.8 \pm 5$ \\
\hline
\end{tabular}

Nominal device diameter: Stent diameter at nominal inflation pressure. \pm : Standard deviation.

ns: non-significant.

MLD: Mean lumen diameter.

With the routine use of drug-eluting stents, a lower restenosis rate can be anticipated. However, the costs of routine use of DES implants are high. A recent costeffectiveness analysis for DES showed that these devices are cost effective when the TVR rate of BMS exceeds $12 \%$ [3].

The present pilot study was designed to demonstrate the feasibility of using short stenting in lesions with a $<10 \%$ probability of restenosis and implanting DES in all other lesions. In keeping with the results of the former investigation, a single short BMS was sufficient in the majority of interventions $(252 / 310,81.3 \%)$. There was a nearly $1: 1$ match of the stent and the lesion length. The resulting restenosis rate was within the range found in larger trials for the given stent dimensions used $[13,16]$.

Our protocol included percutaneous transluminal coronary angioplasty as the initial procedure for most lesions. Balloon dilatation alone achieved a low residual stenosis in only a few lesions; however, it did reduce the length of obturating plaques responsible for diameter stenoses $>30 \%$. This shortening of the significant portions of the lesions contributed to the high number of lesions that could be treated adequately with single short stents. In $5.4 \%$ of these lesions, however, their length was underestimated or a stent was misplaced, thereby requiring an additional stent, which contributed to restenosis found in the short BMS group. Plaques that were adjacent to a BMS

Table 4: Clinical and angiographic outcomes

\begin{tabular}{ll}
\hline Variable & All lesions $\mathrm{n}=236$ \\
\hline Angiographic success & $230(97.5 \%)$ \\
Procedural success & $194 / 200(97.0 \%)$ \\
Final minimum lumen diameter $(\mathrm{mm})$ & $2.9 \pm 0.3$ \\
Final diameter stenosis $(\%)$ & $15 \pm 12$ \\
Acute gain $(\mathrm{mm})$ & $2.2 \pm 0.3$ \\
Final plaque area $\left(\mathrm{mm}^{2}\right)$ & $2.8 \pm 2.2$ \\
\hline
\end{tabular}

and that caused luminal narrowing $<45 \%$ exhibited no increased frequency of restenosis. This finding is consistent with previous investigations, in which incomplete plaque coverage was not associated with increased risk for restenosis.

In conjunction with the strategy of incomplete plaque coverage, Colombo et al. introduced the concept of 'spot stenting' long lesions ( $>15 \mathrm{~mm}$ ). These researchers compared a) complete coverage of a treated long lesion to b) stenting only those stenosis segments that did not meet pre-defined intravascular ultrasound criteria for successful treatment after initial balloon dilatation [17]. They observed a lower restenosis rate in the latter group. Indeed, restricting stent surface to the minimum necessary area might reduce proliferative responses of the arterial wall to the stent $[18,19]$.

Our findings regarding DES are comparable to those from a larger investigation of more complex lesions [1]. The overall restenosis rate of $8.4 \%$ and the TVR rate of $7.4 \%$ noted with the differential use of short bare metal stenting and DES implantation raises the question of use of DES implantation in all lesions, in terms of economic considerations. Moreover, none of the observed restenoses were diffuse or proliferative after single short BMS, a finding that is compatible with a high long-term success rate after reintervention [20].

\section{Methodological aspects}

An exact determination of lesion length was crucial to the interpretation of angiographic results. The criterion used to measure lesion length by quantitative angiography (length of plaque causing $>50 \%$ diameter reduction) reflects more precisely the extent of clinically relevant stenoses and makes it possible to standardize measurements, in contrast to overall lesion length as used by many automated contour detecting systems. However, lesion length as measured by the criterion described above is 
Table 5: Angiographic follow-up

\begin{tabular}{ll}
\hline Variable & All lesions $\mathrm{n}=2 \mathrm{I} 5$ \\
\hline Percent diameter stenosis & $33 \pm 20$ \\
Minimum lumen diameter $(\mathrm{mm})$ & $2.3 \pm 0.6$ \\
Late loss $(\mathrm{mm})$ & $0.58 \pm 0.5$ \\
Loss index & $26 \pm 15$ \\
Net gain $(\mathrm{mm})$ & $\mathrm{I} .5 \pm 0.7$ \\
Net gain index & $5 \mathrm{I} \pm 24$ \\
Neo-plaque area $\left(\mathrm{mm}^{2}\right)$ & $\mathrm{I} .8 \pm 3.5$ \\
Net plaque reduction $\left(\mathrm{mm}^{2}\right)$ & $6.2 \pm 4$ \\
Restenosis $(\%)$ & $18(8.4 \%)$
\end{tabular}

Net gain index: Net gain / vessel size $\times 100$.

Neo-plaque area: Plaque area at follow-up minus final plaque area.

Net plaque reduction: plaque area before minus plaque area at followup.

Loss index: Late loss / acute gain * 100

\pm : Standard deviation.

usually shorter, as compared to measuring total lesion length. Since the present study was not designed to compare immediate and long-term results of short BMS and DES, we did not perform statistical comparative analysis.

\section{Limitations}

Our criteria for selecting a short BMS implant versus a DES implant for study participants were based on results from a non-randomized study performed earlier at our institution [7]. Selection of the stent device was based on operators' visual interpretation of vessel dimensions. This may, in a few cases, have led to misinterpretation of the actual reference diameter, as demonstrated by quantitative coronary angiography. In these cases, the other stent device was, therefore, implanted. Finally, the study was not randomized, since we intended to prove feasibility of the differential approach in a pilot study. A randomized multicenter trial now seems suitable to elucidate compatibility and cost-effectiveness of this approach with routine DES implantation.

\section{Conclusion}

We demonstrated that: 1) for most lesions, a single short BMS is sufficient to treat the significant part of the stenotic lesion, and 2) the resulting restenosis rate using the single short BMS is low if vessels $>2.7 \mathrm{~mm}$ are treated. Use of DES for all other lesions that could not be treated sufficiently with a short BMS also resulted in a low restenosis rate. These findings suggest a positive synergism between short bare metal stenting and drug-eluting stenting, in terms of reducing costs while achieving overall low restenosis rates in unselected lesions.

\section{Competing interests}

The author(s) declare that they have no competing interests.

\section{References}

I. Hill RA, Dundar Y, Bakhai A, Dickson R, Walley T: Drug-eluting stents: an early systematic review to inform policy. Eur Heart J 2004, 25( I I):902-919.

2. O'Neill WW, Leon MB: Drug-eluting stents: costs versus clinical benefit. Circulation 2003, I07(24):3008-30 I I.

3. Greenberg D, Bakhai A, Cohen DJ: Can we afford to eliminate restenosis? Can we afford not to? J Am Coll Cardiol 2004, 43(4):513-518.

4. Cutlip DE, Chauhan MS, Baim DS, Ho KK, Popma JJ, Carrozza JP, Cohen DJ, Kuntz RE: Clinical restenosis after coronary stenting: perspectives from multicenter clinical trials. J Am Coll Cardiol 2002, 40( I 2):2082-2089.

5. Mauri L, O'Malley AJ, Cutlip DE, Ho KK, Popma JJ, Chauhan MS, Baim DS, Cohen DJ, Kuntz RE: Effects of stent length and lesion length on coronary restenosis. Am J Cardiol 2004, 93(I I ): I 340-6, A5..

6. Dietz U, Holz N, Dauer C, Meinert R, Lambertz H: Short stent implantation for routine use is feasible in a high proportion of coronary interventions and yields a low restenosis rate. Cardiology 2005, I 03(4):212-218.

7. Dietz U, Holz N, Dauer C, Lambertz H: Shortening the stent length reduces restenosis with bare metal stents: matchedpair comparison of short stenting and conventional stenting. Heart 2005.

8. Hausleiter J, Jost S, Nolte CW, Dirschinger J, Kastrati A, Stiel GM, Wunderlich W, Fischer F, Linderer T, Hausmann D, Schomig A: Comparative in-vitro validation of eight first- and secondgeneration quantitative coronary angiography systems. Coron Artery Dis 1997, 8(2):83-90.

9. Dietz U, Rupprecht HJ, Brennecke R, Fritsch HP, Woltmann J, Blankenberg S, Meyer J: Comparison of QCA systems. Int J Card Imaging 1997, I3(4):27I-280.

10. Herrington DM, Walford GD: Optimal frame selection for QCA. In Advances in Quantitative Coronary Arteriography Edited by: Reiber JHC SPW. The Netherlands, Kluwer Academic Publishers; 1993: I 25-135.

II. Reiber JH, van Eldik Helleman P, Visser Akkerman N, Kooijman C], Serruys PW: Variabilities in measurement of coronary arterial dimensions resulting from variations in cineframe selection. Cathet Cardiovasc Diagn 1988, I4(4):221-228.

12. Kastrati A, Mehilli J, Dirschinger J, Pache J, Ulm K, Schuhlen H, Seyfarth M, Schmitt C, Blasini R, Neumann FJ, Schomig A: Restenosis after coronary placement of various stent types. Am J Cardiol 200I, 87( I):34-39.

13. Serruys PW, Kay IP, Disco C, Deshpande NV, de Feyter PJ: Periprocedural quantitative coronary angiography after PalmazSchatz stent implantation predicts the restenosis rate at six months: results of a meta-analysis of the BElgian NEtherlands Stent study (BENESTENT) I, BENESTENT II Pilot, BENESTENT II and MUSIC trials. Multicenter Ultrasound Stent In Coronaries. J Am Coll Cardiol I999, 34(4): I067-I074.

14. Kereiakes D, Linnemeier TJ, Baim DS, Kuntz R, O'Shaughnessy C, Hermiller J, Fink S, Lansky A, Nishimura N, Broderick TM, Popma ]: Usefulness of stent length in predicting in-stent restenosis (the MULTI-LINK stent trials). Am J Cardiol 2000, 86(3):336-34l.

15. Kobayashi Y, De Gregorio J, Kobayashi N, Akiyama T, Reimers B, Finci L, Di Mario C, Colombo A: Stented segment length as an independent predictor of restenosis. I Am Coll Cardiol 1999. 34(3):65I-659.

16. Antoniucci D, Valenti R, Santoro GM, Bolognese L, Trapani M, Cerisano G, Boddi V, Fazzini PF: Restenosis after coronary stenting in current clinical practice. Am Heart J I 998, I35(3):5 I0-5 I8.

17. Colombo A, De Gregorio J, Moussa I, Kobayashi Y, Karvouni E, Di Mario C, Albiero R, Finci L, Moses J: Intravascular ultrasoundguided percutaneous transluminal coronary angioplasty with provisional spot stenting for treatment of long coronary lesions. J Am Coll Cardiol 200I, 38(5): | 427-I 433.

18. Komatsu R, Ueda M, Naruko T, Kojima A, Becker AE: Neointimal tissue response at sites of coronary stenting in humans: macroscopic, histological, and immunohistochemical analyses. Circulation 1998, 98(3):224-233.

19. Inoue T, Sohma R, Miyazaki T, Iwasaki Y, Yaguchi I, Morooka S: Comparison of activation process of platelets and neutrophils 
after coronary stent implantation versus balloon angioplasty for stable angina pectoris. Am J Cardiol 2000, 86 (10): I057-1062.

20. Mehran R, Dangas G, Abizaid A, Lansky AJ, Mintz GS, Pichard AD, Satler LF, Kent KM, Waksman R, Stone GW, Leon MB: Treatment of focal in-stent restenosis with balloon angioplasty alone versus stenting: Short- and long-term results. Am Heart J 200I, |4|(4):6|0-6|4.

Publish with Bio Med Central and every scientist can read your work free of charge

"BioMed Central will be the most significant development for disseminating the results of biomedical research in our lifetime. " Sir Paul Nurse, Cancer Research UK

Your research papers will be:

- available free of charge to the entire biomedical community

- peer reviewed and published immediately upon acceptance

- cited in PubMed and archived on PubMed Central

- yours - you keep the copyright

Submit your manuscript here:

http://www.biomedcentral.com/info/publishing_adv.asp 